\title{
Evaluation of Poultry Manure and Acidified Water for Improving Phosphorus Utilization from Bone Char: A Comparative Study
}

\author{
Amal H. Mahmoud ${ }^{1}$, Maher E. Saleh ${ }^{2 *}$ and Ahmed A. El-Refaey ${ }^{3}$ \\ 1- Soil Salinity and Alkalinity Res. Lab., Soil, Water and Environment Res. Institute, \\ Agric. Res. Center, 2- Department of Soil \& Water Sci., Faculty of Agriculture, and 3- \\ Department of Soil \& Water Science, Faculty of Desert and Environmental Agriculture \\ (Fuka Branch), Alexandria University, Alexandria, Egypt.
}

\begin{abstract}
NIMAL bone char (BC) is, recently, evaluated as one of potentially sustainable sources of phosphate fertilizer to face the accelerated depletion of mined phosphate rock (PR). Further explorations are needed to investigate its behavior when applied to soils in comparison with direct application of PR. Column leaching and greenhouse experiments were carried out to evaluate and compare the behavior of both BC and PR. Results of column leaching experiments showed that water soluble phosphorus (WSP) released from BC-filled columns represented 5 to 476 folds of that released from PR columns throughout the experiment period. Mixing poultry manure (PL) with BC or PR enhanced rate of columns leaching of WSP particularly with increasing the rate of application. Leaching by acidified water significantly increased the solubility of BC-P and PR-P compared with those released in water leachates. Similar increases were only obtained in PL:BC mixtures whereas the increases in acidified WSP were observed only in PR columns and did not occurred in PL:PR mixtures. Besides the occurrence of organic fractions of $\mathrm{P}$ in $\mathrm{BC}$, poultry litter degradation derivatives are, probably, serve as potential complexing legends with calcium and cause a further release of $\mathrm{P}$ from $\mathrm{BC}$ in water leachate. While the huge amounts of protons $\left(\mathrm{H}^{+}\right)$in acidified water play a crucial role in apatite dissolution in both sources (BC and PR). Results of P availability after leaching showed that Olsen-P was greatly higher in all columns of BC than PR. In BC columns, concentrations of formic acid-P and citric acid-P resulted from water leached columns were higher than those resulted from acidified water leached ones while; there was no significant changes in PR columns. The higher solubility and availability of BC-P than PR-P were translated in higher biomass and grain yield of maize treated by BC-P in comparison with those treated with PR-P and their mixtures with PL.
\end{abstract}

Keywords: Animal waste, Sustainable phosphate source, Poultry litter, Phosphate rock, P availability.

\section{Introduction}

Phosphorus $(\mathrm{P})$ is an essential macronutrient that is critically needed for the normal functioning of ecosystems and has no substitute in food production. The availability of soil native $\mathrm{P}$ to plant growth and organisms' propagation is seldom covering their requirements and thus application of $\mathrm{P}$ fertilizers is recommended to increase soil productivity. According to the $\mathrm{P}$ fertilizer industry records, phosphate rock as a non-renewable row material of $\mathrm{P}$, which is going towards depletion (Koppelaar \& Weikard, 2013). It is estimated that demand would outstrip supply of rock phosphate in the next 50-100 years (Smil, 2000; Cordell et al., 2009; Gilbert, 2009). The phosphorus scarcity challenge means that other sources of $\mathrm{P}$ has to be recovered for reuse as fertilizers to substitute phosphate rock (Cordell et al., 2011). Phosphorus recovery from waste materials is considered as one of the major solutions to overcome the current depletion in mined-P resources all over the world. Economically and technically, the recovery of $P$ from animal wastes is the most suitable and tractable solution. (Rittmann et al., 2011).

Animal bones belong to the group of phosphorus-rich wastes. Calcium phosphates are 
the primary constituents of bones. Bone mineral structure is commonly classified as biogenic apatite (LeGeros, 1994; Deydier et al.,2005, Wopenka \& Pasteris, 2005; Zwetsloot et al., 2014). The incorporation of animal bones in fertilizers is the only rational way of managing it, especially after the EU prohibited the use of meat and bone meal in animal feed after crisis of the bovine spongiform encephalopathy (BSE). High-temperature of pyrolysis during charring animal bones may overcome this problem through incineration and heat sterilization (European Union, 2002; Chaala \& Roy, 2003; Jeng et al. 2006; Cascarosa et al., 2012). Warren et al. (2009), Weber et al. (2014), El-Refaey et al. (2015), Zwetsloot et al., (2014 and 2016); Buss et al. (2016) have shown that $P$ in bone char is as effective as mineral $\mathrm{P}$ fertilizers besides being more economic alternative. X-ray diffraction patterns of bone char and phosphate rock displayed evident similarities and pointed out to the analogy between the structures of PR-apatite and bone char -apatite mineral. Moreover, water soluble-P, Olsen-P, formic acid-P and citric acid-P extracted from bone char showed higher concentrations than those obtained from PR (El-Refaey et al., 2015). Moreover, nearly null or low concentrations of heavy metal contents, such as $\mathrm{Pb}, \mathrm{Ni}, \mathrm{Cr}$ and $\mathrm{Cd}$ could be found in bone char compared with phosphate rock and/or triple superphosphate (Deydier et al., 2005; Siebers \& Leinweber, 2013; El-Refaey et al., 2015). Warren et al. (2009) reported that the facts of the soils and circumstances when PR is useful as a fertilizer can be applied also to bone char. So, the soil factors that control P dissolution for phosphate rock appears to the same for bone char. This soil properties were those associated to soil acidity and the more exchangeable acidity and lower the $\mathrm{pH}$, the greater the dissolution of bone char. To be utilized by plants, phosphorus should first be dissolved. Several attempts were used to increase the efficiency of PR-P solubilization including using the acidifier microbes (Bianco \& Defez, 2010; Vassilev et al., 2013; Sharma et al., 2013; Mendes et al., 2014), organic manure and organic acids (Al-Oud, 2011) or even through plant exudates (Hinsinger, 2001; Hinsinger et al., 2003; Rengel \& Marschner, 2005). P-recovery by acid leaching is one of the traditional methods and sulphuric acid is considered the economic most common leaching agent used for solubilising $\mathrm{P}$ from phosphate rock (Franz , 2008; Petzet et al., 2012; Atienza-Marti'nez al., 2014). Poultry litter, mixture of poultry manure and bedding materials, is valuable amendments acidic conditions in the soil (Brown et al. 2005; Xie et al., 2015) and can be effectively contribute in increasing P solubilization.

In the present investigation, the dissolution and bioavailability of $\mathrm{P}$ in bone char produced by thermo-chemical conversion was evaluated its suitability to substitute rock phosphate to overcome limited $\mathrm{P}$ resources and also assess the ability of bone char as a P-amendment to improve plant growth and $\mathrm{P}$ availability in soil. $\mathrm{P}$ recovery from $\mathrm{BC}$ and $\mathrm{PR}$ was studied using leaching column experiment by distilled water and acidified water amended with different ratios of poultry litter. In addition, P-uptake by maize from amended soil with $\mathrm{BC}$ was considered in comparison with PR.

\section{Materials and Methods}

\section{Materials}

The animal (cattle) bone was collected from the local market (Alexandria, Egypt), leached with diluted acid solution (0.005 $\left.\mathrm{M} \mathrm{HNO}_{3}\right)$, then leached several times with deionized water for discard meat residues and oven-dried for 24 hours at $70{ }^{\circ} \mathrm{C}$. Dried animal bones were then converted into bone char (BC) through thermo-chemical conversion at $650^{\circ} \mathrm{C}$ for 2 hours according to El-Refaey et al. (2015). Phosphate rock (PR) was purchased from El-Nasr Mining Company, Aswan, Egypt. Both BC and PR were crushed by hand in a porcelain mill, passed through $0.5-\mathrm{mm}$ polypropylene sieve and stored in plastic bottles. Table (1) summarized elemental analysis and $\mathrm{P}$ fractions of BC and PR (El-Refaey et al., 2015).

Poultry litter (PL) was obtained from the Poultry Farm of Agricultural Research Station, Faculty of Agriculture, Alexandria University. PL was oven-dried for $48 \mathrm{~h}$ at $60{ }^{\circ} \mathrm{C}$ and the contents of carbon, phosphorus and calcium were analyzed as outlined by Crompton (2000) then the $\mathrm{Ca} / \mathrm{P}$ ratio was calculated. PL contained $25.2 \% \mathrm{C}$, $3.43 \% \mathrm{P}_{2} \mathrm{O}_{5}$ and $3.5 \% \mathrm{CaO}$ and calculated $\mathrm{Ca} / \mathrm{P}$ ratio was 1.44 .

Sand samples used in the experiments were treated by diluted hydrochloric acid, for two days, to decompose carbonates (Tributh and Lagaly, 1986), citrate-dithionite solution to dissolve oxides and hydroxides(Stul and van Leemput, 1982) and hydrogen peroxide to oxidize organic matter (Anderson, 1961). Samples were then leached several times by distilled water then dried at $105^{\circ} \mathrm{C}$ for $24 \mathrm{~h}$ and stored in plastic jars. 
TABLE 1: Elemental analysis and $P$ fractions of bone char (BC) and phosphate rock (PR).

\begin{tabular}{|c|c|c|c|c|}
\hline Measured parameters & \multicolumn{2}{|c|}{ BC } & \multicolumn{2}{|c|}{ PR } \\
\hline \multicolumn{5}{|l|}{ Total content (\%) } \\
\hline $\mathrm{P}_{2} \mathrm{O}_{5}$ & \multicolumn{2}{|c|}{36.07} & \multicolumn{2}{|c|}{33.21} \\
\hline $\mathrm{CaO}$ & \multicolumn{2}{|c|}{38.08} & \multicolumn{2}{|c|}{35.24} \\
\hline $\mathrm{Ca} / \mathrm{P}$ ratio & \multicolumn{2}{|c|}{1.73} & \multicolumn{2}{|c|}{1.74} \\
\hline $\mathrm{C}$ & \multicolumn{2}{|c|}{5.86} & \multicolumn{2}{|c|}{0.28} \\
\hline $\mathrm{N}$ & \multicolumn{2}{|c|}{1.95} & \multicolumn{2}{|c|}{0.18} \\
\hline Total carbonate & \multicolumn{2}{|c|}{6.21} & \multicolumn{2}{|c|}{10.45} \\
\hline \multicolumn{5}{|l|}{ Heavy metals (mg kg ${ }^{-1}$ ) } \\
\hline $\mathrm{Cd}$ & \multicolumn{2}{|c|}{2.50} & \multicolumn{2}{|c|}{7.20} \\
\hline $\mathrm{Cr}$ & \multicolumn{2}{|c|}{6.50} & \multicolumn{2}{|c|}{91.00} \\
\hline $\mathrm{Pb}$ & \multicolumn{2}{|c|}{$\mathrm{nd}^{*}$} & \multicolumn{2}{|c|}{ nd } \\
\hline $\mathrm{Cu}$ & \multicolumn{2}{|c|}{ nd } & \multicolumn{2}{|c|}{7.75} \\
\hline $\mathrm{Fe}$ & \multicolumn{2}{|c|}{17.00} & \multicolumn{2}{|c|}{12.50} \\
\hline $\mathrm{Mn}$ & \multicolumn{2}{|c|}{8.00} & \multicolumn{2}{|c|}{13.00} \\
\hline $\mathrm{Ni}$ & \multicolumn{2}{|c|}{ nd } & \multicolumn{2}{|c|}{ nd } \\
\hline$\underline{P \text { fractions }}$ & $\mathrm{mg} \mathrm{g}^{-1}$ & $\%$ of total $P$ & $\mathrm{mg} \mathrm{g}^{-1}$ & $\%$ of total $P$ \\
\hline$\overline{\text { WS- } \mathrm{P}_{2} \mathrm{O}_{5}}$ & 0.44 & 0.12 & 0.05 & 0.02 \\
\hline Olsen- $\mathrm{P}_{2} \mathrm{O}_{5}$ & 3.44 & 0.95 & 0.12 & 0.04 \\
\hline FA- $\mathrm{P}_{2} \mathrm{O}_{5}$ & 312.95 & 86.77 & 170.38 & 51.31 \\
\hline $\mathrm{CA}-\mathrm{P}_{2}^{2} \mathrm{O}_{5}$ & 139.30 & 38.62 & 105.34 & 31.72 \\
\hline
\end{tabular}

- nd: not detected.

\section{Column Leaching Experiment}

A leaching column experiment was carried out in Pyrex glass column $(2.0-\mathrm{cm}$ in diameter and $14.0-\mathrm{cm}$ in height). Glass wool plugs $(2-\mathrm{cm}$ distance) at the base of the columns was used to maintain and facilitate continuous flow of leaching solutions. Columns were then packed with washed sand (equivalent to 25 grams dry weight) together with one of the following treatments i.e. 25.0 grams of $\mathrm{BC}, 25.0 \mathrm{~g}$ PR or with ratios of $\mathrm{BC}$ (or PR): PL equal 25:0(CR0), 25:2.5 (CR1), 25:5 (CR2) or 25:12.5 (CR3). Columns were initially flushed with distilled water for $2 \mathrm{~h}$ and the volume of flushed water was collected to represent zero time sampling. Afterwards, columns were splitted into two groups; the first ones were leached with distilled water and the others were leached with acidified water $\left(0.005 M \mathrm{H}_{2} \mathrm{SO}_{4}\right)$. A peristaltic pump (ISMATEC ISM 931, Switzerland) was used to flow the influents of the column to maintain a constant upward flow rate in the column equals $0.25 \mathrm{~mL} \mathrm{~min}^{-1}$. Leachates were collected daily for 30 days and analyzed for their $\mathrm{pH}$ and $\mathrm{P}$-contents. At the end of leaching experiment, the columns were evacuated and their contents were ovendried at $105{ }^{\circ} \mathrm{C}$ for 24 hours. Then, the ovendried contents were crushed and sieved using $0.5-\mathrm{cm}$ polypropylene sieve. Various extractable fractions: water soluble (WS-P), Olsen (O-P), 2\% formic acid(FA-P) and 2\% citric acid (CA-P), were determined in each column.

\section{Water soluble $P(W S-P)$ :}

One gram of the sample was transferred into $250-\mathrm{mL}$ conical flasks then $50 \mathrm{~mL}$ distilled water was added and the flask was shaken for one hour. The suspensions were filtered using filter paper Whatman No. 42 and $P$ concentration was determined in the supernatants.

\section{Olsen P fraction:}

According to Murphy \& Riley (1962), $2.0 \mathrm{~g}$ sample was shacked for 30 minutes with $40.0 \mathrm{~mL} \mathrm{0.5} \mathrm{M}$ sodium bicarbonate $\left(\mathrm{NaHCO}_{3}\right)$ solution adjusted to $\mathrm{pH} 8.5$ with $0.01 \mathrm{~mol} \mathrm{~L}^{-1}$ $\mathrm{NaOH}$ or $0.01 \mathrm{~mol} \mathrm{~L}^{-1} \mathrm{HCl}$. Suspensions were filtered through filter papers Whatmann No. 42 and $\mathrm{P}$ was then measured in supernatants.

Formic acid-P fraction (FA-P)

A $0.4 \mathrm{~g}$ sample was extracted with $40 \mathrm{~mL}$ $2 \%$ formic acid at $23{ }^{\circ} \mathrm{C}$ for 1 hour (Hoffman \& Mager, 1953). The samples were then centrifuged at $10,000 \mathrm{rpm}$ for $5 \mathrm{~min}$. and filtered using $0.45 \mu \mathrm{m}$ Millipore filter.

\section{Citric acid-P fraction (CA-P)}

$0.4 \mathrm{~g}$ soils were shaken with $40 \mathrm{~mL} 2 \%$ citric acid at $23{ }^{\circ} \mathrm{C}$ for 1 hour. The samples were then centrifuged at $10,000 \mathrm{rpm}$ for $5 \mathrm{~min}$, filtered using $0.45 \mu \mathrm{m}$ Millipore filter and the residue was extracted again with another $40 \mathrm{~mL}$ of $2 \%$ fresh citric acid. 
Concentration of phosphorus was measured colorimetrically using ascorbic acid-molybdate blue method (Olsen \& Sommers, 1982) at wavelength $882 \mathrm{~nm}$ or using vanado-molybdate yellow method at wavelength $445 \mathrm{~nm}$ (Chapmann \& Pratt, 1961) depending on the concentration ranges of $\mathrm{P}$ as mentioned above using UV/VIS double beam JENWAY spectrophotometer model 6850. All $\mathrm{P}$ concentrations and $\mathrm{pH}$ measurements were carried out in duplicate.

\section{Greenhouse experiment}

The phytoavailability of $\mathrm{P}$ in bone char was examined through evaluating $\mathrm{P}$ - uptake by maize plants versus phosphate rock. The experiment was laid out in a randomized complete block design with four replicates of plots $(120 \mathrm{~cm} \mathrm{x}$ $70 \mathrm{~cm}$ ) containing clay soils. Soil properties are listed in Table 2 and located according to global positioning system (GPS) at " 26.56 '29'56 east and " 02.11 ' $31^{\circ} 13$ north. The plot received a fixed rate of applied $\mathrm{P}$ equivalent to $46 \mathrm{~kg} \mathrm{P}$ per hectare based on P-content in the different P-sources. The experimental treatments were as follows: PR or $\mathrm{BC}$ applied either solely or in mixtures with PL i.e. $10 \% \mathrm{PL}+90 \% \mathrm{PR}(\mathrm{BC}), 20 \% \mathrm{PL}+80 \% \mathrm{PR}(\mathrm{BC})$, $50 \% \mathrm{PL}+50 \% \mathrm{PR}(\mathrm{BC})$.Seeds of maize cultivar (Giza176, monohybrid) were then sown, in all plots, in two rows, four plants per row and all plots received the recommended dose of $\mathrm{N}$ and $\mathrm{K}$ as recommended by the Ministry of Agriculture. Soil properties are listed in Table (2). BC and PR and their ratios with PL which represented the $\mathrm{P}$ fertilizer were applied to soil with $\mathrm{N}$ and $\mathrm{K}$. The applied rate of $\mathrm{P}$ was $105 \mathrm{~kg} \mathrm{P}_{2} \mathrm{O}_{5}$ per hectare based on the content of $\mathrm{P}_{2} \mathrm{O}_{5}$ in $\mathrm{BC}$ and $\mathrm{PR}$. This rate of applied $\mathrm{P}$ was fixed and PL was added by 10,20 and $50 \%$ of applied phosphate (the treatments were $105 \mathrm{~kg} \mathrm{P}_{2} \mathrm{O}_{5}$ (R0), $105 \mathrm{~kg} \mathrm{P}_{2} \mathrm{O}_{5}+10.5 \mathrm{~kg} \mathrm{PL}$ (R1), $105 \mathrm{~kg} \mathrm{P}_{2} \mathrm{O}_{5}+21 \mathrm{~kg} \mathrm{PL}(\mathrm{R} 2)$ and $105 \mathrm{~kg} \mathrm{P}_{2} \mathrm{O}_{5}+52.5$ $\mathrm{kg}$ PL (R3)). Potassium was applied at the rate of $50 \mathrm{~kg} \mathrm{~K}$ per hectare in the form of potassium sulfate and Nitrogen application was divided to three dose $60 \mathrm{~kg} \mathrm{~N}$ per hectare). All additives were thoroughly mixed in the $15-\mathrm{cm}$ soil surface before sowing. Irrigation schedule was conducted according to maintain the moisture content in soil at approximately field capacity. Leaf samples were taken at tasseling growth stage for detecting the $\mathrm{P}$ and $\mathrm{Ca}$ uptake. At the physiological maturity growth stage (harvest), plant height, total biomass and grain yield were estimated.

The obtained results were statistically analyzed and analysis of variance was conducted using Costat software (Costat, 1985).

TABLE 2. Some soil physicochemical properties.

\begin{tabular}{cccccccc}
\hline Sand & Silt & Clay & $\mathbf{p H}$ & $\begin{array}{c}\mathbf{E C} \\
\mathbf{d S ~ \mathbf { m } ^ { - 1 }}\end{array}$ & $\begin{array}{c}\mathbf{C a C O} \\
\mathbf{\%}\end{array}$ & $\begin{array}{c}\text { O.M } \\
\mathbf{\%}\end{array}$ & $\begin{array}{c}\text { Olsen-P } \\
\mathbf{m g ~ k g}^{-1}\end{array}$ \\
\hline 6.21 & 18.20 & 75.59 & 7.42 & 3.37 & 3.98 & 1.03 & 4.21 \\
\hline
\end{tabular}

\section{Results}

\section{Effect of Poultry litter mixing on P leaching \\ Leaching by water}

Daily phosphorus released in the leachates of columns filled with either BC or PR with/without the poultry litter (PL) versus time is presented in Fig 1. Water soluble phosphorus (WSP) recorded about $400 \mathrm{mg} \mathrm{kg}^{-1}$ at the beginning of the incubation period. These concentrations decreased with time in $\mathrm{BC}$ columns until the $10^{\text {th }}$ day then slightly increased afterwards. With respect to PR, concentrations of WSP were relatively lower and almost no changes occurred in the WSP amount in leachate along with the studied period (see Table 3). The amounts of daily phosphorus in the leachate from BC columns by water were about 5 to 476 fold higher than the corresponding ones leached out from the PR columns.
Mixing of $\mathrm{PL}$ with either $\mathrm{BC}$ or $\mathrm{PR}$ increased generally the concentration of WSP in the leachate. Increasing the rate of applied $\mathrm{PL}$ resulted in further increases in the rates of leaching $\mathrm{P}$ from $\mathrm{BC}$ or PR columns (Table 3). Addition of PL to $\mathrm{BC}$ columns increased the rate of the leached $\mathrm{P}$ and the concentration of released $\mathrm{P}$ increased proportionally with increasing the rate of applied. Likewise, the released P from PR columns increased significantly when amended with PL especially at its high rates (Table 3). Values of $\mathrm{pH}$ of leachate markedly decreased with time in the leachate of BC columns (9.287.29) while did not vary significantly $(7.5-8.1)$ in the PR columns (Table 4). Further reductions in $\mathrm{pH}$ were detected with mixing of PL with $\mathrm{BC}$ and vice versa with PR. Also, these trends in $\mathrm{pH}$ changes were observed with the increase of PL:BC (or PR) ratios (Table 4). 


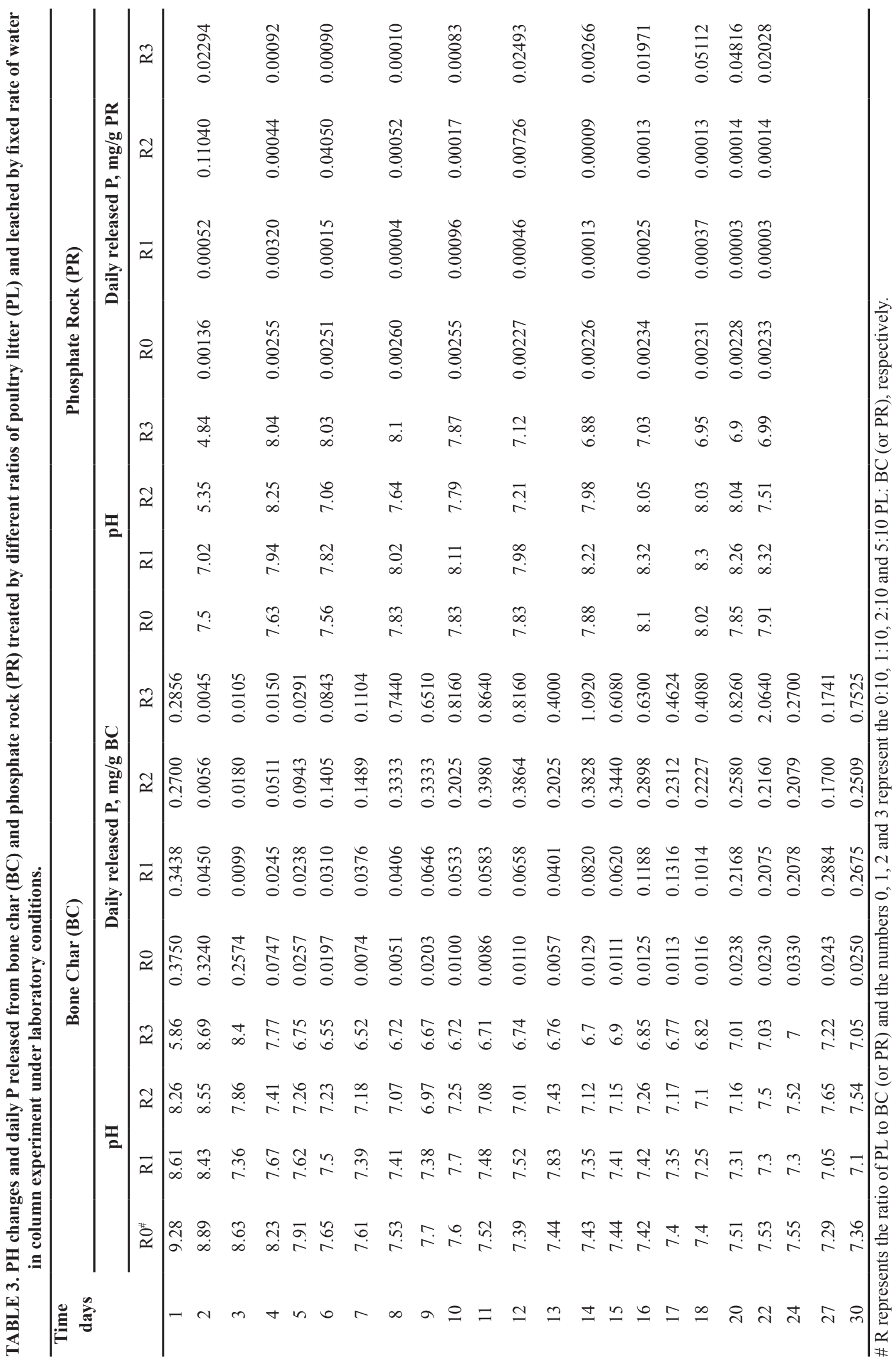

Egypt. J. Soil Sci. 57 No. 2 (2017) 


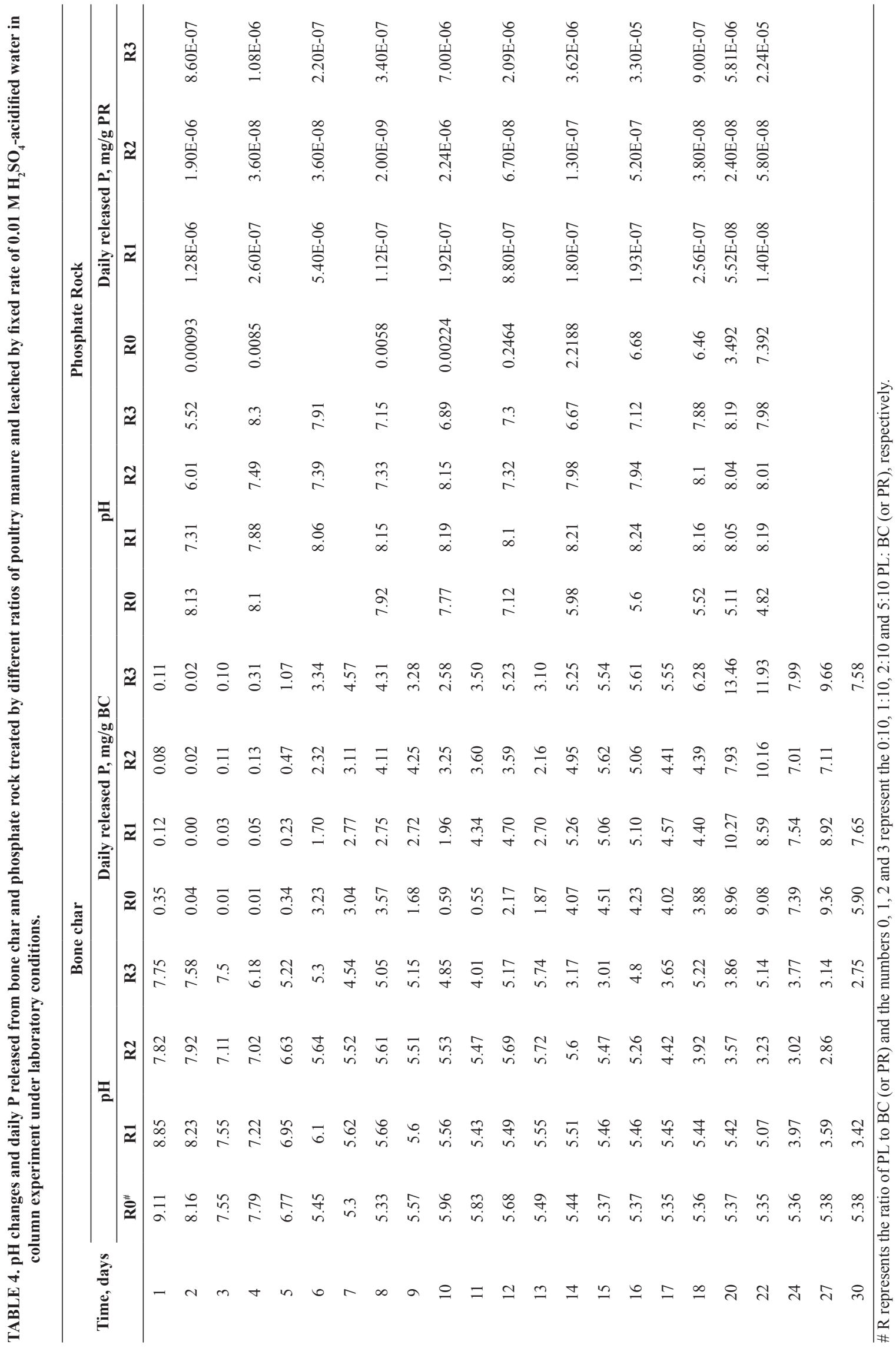

Egypt. J. Soil Sci. 57 No.2 (2017) 


\section{Leaching of $P$ by acidified water}

Table 4 presents the leachate of $\mathrm{P}$ from the different investigated sources of P i.e. BC and PR using acidified-water. Such dilute acid probably resembles the effect of root exudates thus increasing the release of $\mathrm{P}$ and its solubility from both sources (Table 4). With time, the released amount of $\mathrm{P}$ from the leachates of $\mathrm{P}$ from $\mathrm{BC}$ columns remained relatively unchanged until the $4^{\text {th }}$ or $5^{\text {th }}$ day and increased afterwards while in PR colums no $\mathrm{P}$ was detected in the leachate up to 12 days of incubation and increased thereafter. Increasing the rate of applied PL in the PL-BC mixtures led to further increases in the released amounts of $\mathrm{P}$ whereas the vice versa was observed in PL-PR mixtures (Table 4).

The $\mathrm{pH}$ values of acidified-water leachates significantly decreased with the progress of leaching days and also decreased with increasing $\mathrm{PL}$ incorporation with $\mathrm{BC}$ while, mixing of PL with PR rendered the decrease in $\mathrm{pH}$ (Table 4).

\section{Phosphorus availability after leaching \\ Water Extracted-P (WEP)}

Results of water extracted-P are presented in Table 5. The amount of WEP obtained after leaching of $\mathrm{BC}$ by water was less than that obtained after leaching by acidified-water. Mixing of PL with BC increased the WEP in both kinds of leaching and WSP increased with increasing the PL:BC ratios. Similar trends were observed in the columns packed with PR and PLPR mixtures (Table 5).

Olsen Extracted-P (OEP)

The extracted P by $0.5 M \mathrm{NaHCO}_{3}$ solution (adjusted at $\mathrm{pH}$ 8.5) reflects the phytoavailability of soil phosphorus regardless of the source of $\mathrm{P}$ amendment. After 30 day-leaching of $\mathrm{BC}$ and $\mathrm{BC}+\mathrm{PL}$ columns (or 22day-leaching in case of $\mathrm{PR}+/-\mathrm{PL})$, sodium bicarbonateextracted P (Olsen P) was determined to get the residual available $\mathrm{P}$ concentration. Generally, OEP extracted from columns leached with acidified water was higher (1.5 and 2.6 times, respectively) than those obtained after columns leached with none acidified deionized water (Table 5). Also, application of PL to either BC or PR increased noticeably the amounts of OEP especially at its higher rates of application.

\section{Formic acid-extracted $P$ (FAP)}

The extracted $\mathrm{P}$ by $2 \%$ formic acid or $2 \%$ citric acid solutions reflects the agronomic effectiveness of $\mathrm{BC}$ and $\mathrm{PR}$ as $\mathrm{P}$ amendments for the soil. In general, the amounts of FAP extracted with water leaching were higher than those extracted with acidified-water leaching except in the treatment PL:PR 5:10 (Table 5).

\section{Citric acid-extracted $P(C A P)$}

According to the results presented in Table 5 , the concentration of CAP remained after water leaching of $\mathrm{BC}$ columns was higher than the remained after acidified-water leaching in all treatments of $\mathrm{BC}$. In acidified-water leached columns of BC, the CAP decreased as PL:BC increased (Table 5). The concentration of CAP in PR columns leached by water was higher than that leached by acidified-water. On the other hand, CAP of PL-PR mixtures were higher in acidifiedwater than in water leached ones (Table 5).

TABLE 5. Bioavailability of residual $P\left(\mathrm{mg} \mathrm{g}^{-1}\right)$ extracted by water, Olsen extract, formic acid and citric acid after 30 and 22 days leaching of bone char (BC) and phosphate rock, respectively, by water or acidified water.

\begin{tabular}{|c|c|c|c|c|c|c|c|c|}
\hline \multirow{3}{*}{$\begin{array}{l}\text { Extracted } \\
\text { form of } P\end{array}$} & \multicolumn{4}{|c|}{ After water leaching } & \multicolumn{4}{|c|}{ After acidified water leaching } \\
\hline & \multicolumn{8}{|c|}{ Bone Char (BC) } \\
\hline & BC & $\begin{array}{c}\text { PL:BC } \\
1: 10\end{array}$ & $\begin{array}{c}\text { PL:BC } \\
2: 10\end{array}$ & $\begin{array}{c}\text { PL:BC } \\
5: 10\end{array}$ & BC & $\begin{array}{c}\text { PL:BC } \\
1: 10\end{array}$ & $\begin{array}{c}\text { PL:BC } \\
2: 10\end{array}$ & $\begin{array}{c}\text { PL:BC } \\
5: 10\end{array}$ \\
\hline WSP & 0.048 & 0.209 & 0.343 & 0.490 & 0.124 & 0.142 & 0.148 & 0.213 \\
\hline OP & 1.230 & 2.320 & 1.550 & 0.780 & 1.870 & 1.460 & 1.560 & 0.640 \\
\hline FAP & 68.500 & 67.000 & 68.250 & 43.250 & 32.188 & 28.625 & 23.500 & 7.250 \\
\hline \multirow[t]{3}{*}{ CAP } & 47.350 & 61.375 & 70.750 & 54.250 & 37.500 & 33.000 & 25.500 & 17.125 \\
\hline & \multicolumn{8}{|c|}{ Phosphate Rock (PR) } \\
\hline & PR & $\begin{array}{c}\text { PL:PR } \\
1: 10 \\
\end{array}$ & $\begin{array}{c}\text { PL:PR } \\
2: 10 \\
\end{array}$ & $\begin{array}{c}\text { PL:PR } \\
5: 10 \\
\end{array}$ & PR & $\begin{array}{c}\text { PL:PR } \\
1: 10 \\
\end{array}$ & $\begin{array}{c}\text { PL:PR } \\
2: 10 \\
\end{array}$ & $\begin{array}{c}\text { PL:PR } \\
5: 10 \\
\end{array}$ \\
\hline WSP & 0.007 & 0.074 & 0.053 & 0.149 & 0.308 & 0.050 & 0.058 & 0.100 \\
\hline $\mathrm{OP}$ & 0.089 & 0.008 & 0.041 & 0.340 & 0.232 & 0.153 & 0.140 & 0.219 \\
\hline FAP & 39.500 & 44.500 & 38.250 & 29.375 & 29.625 & 34.875 & 36.250 & 36.250 \\
\hline CAP & 44.350 & 35.938 & 36.813 & 30.688 & 31.125 & 36.413 & 38.250 & 33.600 \\
\hline
\end{tabular}


Response of maize Yield to applied $B C$ and $P R$

Results of biomass of maize showed that application of $\mathrm{P}$ in the form of $\mathrm{BC}$ increased the yield by 36.8 and $56.5 \%$ over control and PR application treatments, respectively (Table 6). Further increases in biomass yield were obtained as a result of PL mixing with $\mathrm{BC}$ and PR. With respect to the PR applications, the biomass yield increased only in the PL: PR mixtures and the increases were proportional to the increase in applied PL in soil.

Similar trends were observed on the maize grain yield which significantly increased with application of BC compared with PR (Table 6). About $31.8 \%$ of grain yield increased as a result of only $\mathrm{BC}$ application whereas about $11.2 \%$ decreased in yield as a result of PR application comparing with control treatment. Incorporation of poultry litter in soil with either bone char or phosphate rock led to significant increases in grain yield. Grain yield increased about 33.2, 66.9 and $92.7 \%$ when PL mixed with $\mathrm{BC}$ at rates of 10,20 and $50 \%$, respectively, whereas such increases were 16.7, 25.5 and 38.2\% when PL mixed with RP at corresponded percentages. Previous studies showed relatively similar results related to mixing and/or composting of PL with PR and its influence on crop yield such as maize and cowpea grown in acid soils (Akande et al., 2005) and wheat crop grown in a basic soil (Sharif et al., 2013).

\section{Uptake of $P$ and Ca by Maize}

Uptake of $\mathrm{P}$ and $\mathrm{Ca}$ by maize plants grown under the greenhouse conditions as affected by the source of P-amendment (BC or PR) in presence or absence of PL were shown in Table 6. Both phosphorus and calcium contents in ear-leaf were higher in the plants fertilized by $\mathrm{BC}$ than those fertilized by PR. Application of PL to both BC-P and PR-P lead to noticeable significant increases in $\mathrm{P}$ and Ca uptake particularly for PL:BC (or PR) $5: 10$. Therefore, the values of $\mathrm{P}: \mathrm{Ca}$ ratio showed the beneficiary of fertilization by $\mathrm{BC}$ and PL coapplication with $\mathrm{BC}$ and $\mathrm{PR}$ for increasing $\mathrm{P}$ and Ca uptake by maize plants (Table 6).

\section{Discussions}

Application of phosphate rock (PR) is one of the regular methods worldwide to enrich acid soils with P (Duarte et al., 2015). However, in soils, PR application seemed to be less effective as dissolution and availability decreased noticeably under these alkaline conditions Thus, introducing bone char $(\mathrm{BC})$ as a competitor to $\mathrm{PR}$ might be the challenge to attain a potential sustainable and, environmentally safe source of P (El-Refaey et al., 2015 and Warren et al., 2009). Leaching experiments of BC-P and PR-P by water and acidified water showed that the amounts of released BC-P were higher than those released from BC-PL mixtures within the first four days of leaching by water. The highest concentration of released $\mathrm{P}$ was associated with the highest $\mathrm{pH}$ values of leachate. For leaching by water experiments, the relationship was polynomial as follow:

$$
\begin{gathered}
\mathrm{BC}-\mathrm{P}(\mathrm{mg} \mathrm{P} / \mathrm{gm} \mathrm{BC})=0.092(\mathrm{pH})^{2}-1.328 \mathrm{pH}+ \\
4.765\left(\mathrm{R}^{2}=0.956^{* * *}, \mathrm{n}=23\right) \ldots \ldots .(1)
\end{gathered}
$$

And for leaching by acidified water experiments, the relationship was exponential as follow:

$\mathrm{BC}-\mathrm{P}(\mathrm{mg} \mathrm{P} / \mathrm{gm} \mathrm{BC})=19679 \mathrm{e}^{-1.56 \mathrm{pH}}\left(\mathrm{R}^{2}=\right.$ $0.65 * * *, \mathrm{n}=23)$

which reflects a strong dependence of water soluble BC-P, along with the period of study, on

TABLE 6. Two-way ANOVA for the effect of phosphorus (P sources and poultry litter (PL) ratio on biomass, grain

\begin{tabular}{|c|c|c|c|c|c|c|}
\hline Factor & Treatment & $\begin{array}{c}\text { Biomass } \\
\mathrm{g} / \mathrm{m}^{2}\end{array}$ & $\begin{array}{c}\text { Grain yield } \\
\mathbf{g} / \mathbf{m}^{2}\end{array}$ & $\begin{array}{l}\mathrm{Ca} \\
\%\end{array}$ & $\begin{array}{l}\mathbf{P} \\
\%\end{array}$ & $\mathrm{P} / \mathrm{Ca}$ \\
\hline \multirow[t]{3}{*}{ P sources } & BC & $2814.00 \mathrm{a}$ & $853.44 a$ & $1.43 \mathrm{a}$ & $0.245 \mathrm{a}$ & $0.173 a$ \\
\hline & PR & $1990.00 \mathrm{~b}$ & $641.00 \mathrm{~b}$ & $1.24 \mathrm{~b}$ & $0.159 b$ & $0.131 \mathrm{~b}$ \\
\hline & LSD $(0.05)^{\#}$ & 167.95 & 40.28 & 0.09 & 0.012 & 0.013 \\
\hline \multirow[t]{9}{*}{ PL Ratio } & $0: 10$ & $1983.75 \mathrm{c}$ & $602.63 d$ & $1.32 \mathrm{ab}$ & $0.186 b c$ & $0.143 b$ \\
\hline & $1: 10$ & $2334.50 \mathrm{~b}$ & $682.88 \mathrm{c}$ & $1.23 \mathrm{~b}$ & $0.1828 \mathrm{c}$ & $0.149 \mathrm{~b}$ \\
\hline & $2: 10$ & $2393.50 \mathrm{~b}$ & $799.13 b$ & $1.37 \mathrm{a}$ & $0.201 b$ & $0.146 \mathrm{~b}$ \\
\hline & $5: 10$ & $2896.38 \mathrm{a}$ & $602.63 a$ & $1.41 \mathrm{a}$ & $0.240 \mathrm{a}$ & $0.168 \mathrm{a}$ \\
\hline & LSD (0.05) & 237.52 & 56.96 & 0.129 & 0.016 & 0.018 \\
\hline & \multicolumn{6}{|c|}{ Significance } \\
\hline & P sources & $* * *$ & $* * *$ & $* * *$ & $* * *$ & $* * *$ \\
\hline & PL Ratio & $* *$ & $* *$ & $*$ & $* * *$ & * \\
\hline & Interaction & ns & $* *$ & ns & ns & ns \\
\hline
\end{tabular}
yield of maize and its $P$ and $C a$ uptake at tasseling growth stage.

\# LSD values were calculated using Duncan's multiple range test (MRT),

$* P<0.05 ; * * P<0.01 ; * * * P<0.001 ;$ ns: not significant 
$\mathrm{pH}$ and the released $\mathrm{P}$ in the first four days may be related to mineralization of organic $\mathrm{P}$ compounds (P-O-C) as a result of pyrolysis process. Novotny et al. (2012) stated that, using ${ }^{13} \mathrm{C}-\mathrm{NMR}$ characterization, the carbonization caused a mineralization of the bones and also a probably destruction of protein phosphoryl compounds. On the other hand, association of PL with $\mathrm{BC}$ had positive influences on $\mathrm{P}$ solubilization which probably related to organic derivatives (OD) released during the decomposition of PL. Therefore, the amounts of released $\mathrm{P}$ in water leachates increased with increasing PL to $\mathrm{BC}$ ratio (Table 3 ). The OD can play as precipitation reaction inhibitor of $\mathrm{Ca}-\mathrm{P}$ and this might extend the time of remaining soluble $\mathrm{P}$ in soil (Saleh et al., 2015; Guppy et al., 2005; Genza et al., 2004).

In contrast to the results of $\mathrm{BC}, \mathrm{P}$ leached out by water from PR columns was not significantly correlated with changes in $\mathrm{pH}\left(\mathrm{r}^{2}=0.234, \mathrm{n}=15\right)$. Further increases in the released PR-P were pronounced by leaching with acidified water as the following relationship:

PR-P (mg P/gm PR $)=45016 \mathrm{e}^{-2.27 \mathrm{pH}}\left(\mathrm{R}^{2}=\right.$ $0.884 * * *, \mathrm{n}=23)$.

Application of PL at rates of 10, 20 and $50 \%$ of PR recorded no significant effect on $\mathrm{P}$ leached out the column by the acidified water throughout the experimental period. In absence of PL, acidified water did not increase leached $P$ until the $14^{\text {th }}$ day, afterwards it increases progressively. The characteristics of both PR and PL may affect the dissolution of $\mathrm{P}$ in the column experiment. The high content of calcium carbonate $\left(\mathrm{CaCO}_{3}\right)$ accompanied the structure of PR $(10.45 \%)$ competes with Hydroxyapatite $\mathrm{Ca}_{10}\left(\mathrm{PO}_{4}\right)_{6}(\mathrm{OH})_{2}$ probably reacted with the acidified water, and resulted in releasing protons $\left(\mathrm{H}^{+}\right)$to the surrounding environment according to the following reaction:

$$
\begin{gathered}
\mathrm{CaCO}_{3}+\mathrm{H}_{2} \mathrm{SO}_{4}+\mathrm{H}_{2} \mathrm{O}=\mathrm{CaSO}_{4}+\mathrm{HCO}_{3}^{-}+\mathrm{H}^{+}+ \\
\mathrm{H}_{2} \mathrm{O} \ldots \ldots \ldots \ldots \ldots \ldots(4) \\
\mathrm{Ca}_{10}\left(\mathrm{PO}_{4}\right)_{6}(\mathrm{OH})_{2}+14 \mathrm{H}^{+}=10 \mathrm{Ca}^{2+}+6 \mathrm{H}_{2} \mathrm{PO}_{4}^{-}+ \\
2 \mathrm{H}_{2} \mathrm{O} \ldots \ldots \ldots \ldots \ldots \ldots(5)
\end{gathered}
$$

Further dissolution of PR occurred through continuous acidification and leaching out continuous high supply of protons and removing of the dissolution products (Mahimairaja et al., 1995).Therefore, leaching with $\mathrm{H}_{2} \mathrm{SO}_{4}$-acidified water facilitates a faster and higher amounts of hydrogen ions which reflected in more the release of $\mathrm{P}$ from both sources (PR and BC).

The residual $\mathrm{P}$ in both $\mathrm{BC}$ and $\mathrm{PR}$ and their mixtures with PL was further influenced by leaching effluent (Table 4). Concentrations of $\mathrm{P}$ fractions extracted by formic acid (FAP) and citric acid (CAP) were higher in water-leached columns comparing with those obtained from acidifiedwater leached ones.

It seems that these results are mirror to the amounts of $\mathrm{P}$ released by water and acidified water, respectively. Therefore, leaching $\mathrm{BC}$ (or PR) by acidified water liberates significantly the more easily mobile fractions of $\mathrm{P}$ than the water did; consequently, $\mathrm{P}$ fractions extracted by formic acid (FAP) and citric acid (CAP) were lower in columns leached out with acidified water than the corresponding ones in columns leached with non acidified water. These results are presented in the cumulative P-curves (Figures 1 and 2).

Leaching of BC-P by water or acidified water might be an implement for interpreting what will happen in the field amended with BC as source of $\mathrm{P}$ and irrigate with acidified water to increase the solubility of of $\mathrm{P}$ released to the grown plants. The highest rate of PL mixed with BC or PR gave relatively similar results for residual $\mathrm{P}$ fractions to those attained with acidified water beside of the cumulative $\mathrm{P}$. These results highlight the importance of amending soils with animal manures to liberate $\mathrm{P}$ from the different P-sources (Agyin-Birikorang et al., 2007; Akande et al., 2005).

The results of agronomic effectiveness of $\mathrm{BC}$ versus $\mathrm{PR}$ on maize yield and its uptake of $\mathrm{P}$ and $\mathrm{Ca}$ indicated the importance of $\mathrm{BC}$ as an alternative sustainable source of $\mathrm{P}$ amendment for crops grown in calcareous soils. The beneficial effect of PL addition to BC and PR applied to soil reflected in more bioavailable $\mathrm{P}$ for maize plant (Figure 4 and Table 4, respectively). Organic matter might also may retard adsorption of $\mathrm{P}$ by soil components and this could improve P-solubility in soil for maize plant (Guppy et al., 2005). On the other hand, the previous works on the agronomic effectiveness of partially acidified PR (Agyin-Birikorang et al., 2007; Kumar et al., 1993; Rajan and Watkinson, 1992; Chien and Hammond, 1989) indicated the importance of and applicability of using acidified water to facilitate and release $\mathrm{P}$ from $\mathrm{BC}$ and partially from $\mathrm{PR}$ and its bioavailability to maize plants. The higher $\mathrm{P}$ and Ca uptake by $\mathrm{BC}$-fertilized plants comparing with PR in the single and PL-BC (or-PR) mixtures reflects the beneficial role of PL co-application in $\mathrm{P}$ availability to grown plants in calcareous soil (Fig. 6) which also reflected on higher biomass and grain yields (Fig. 5). Irrigation with acidified water can play significant roles in controlling $\mathrm{P}$ release and availability from nontraditional P-sources e.g. BC . 

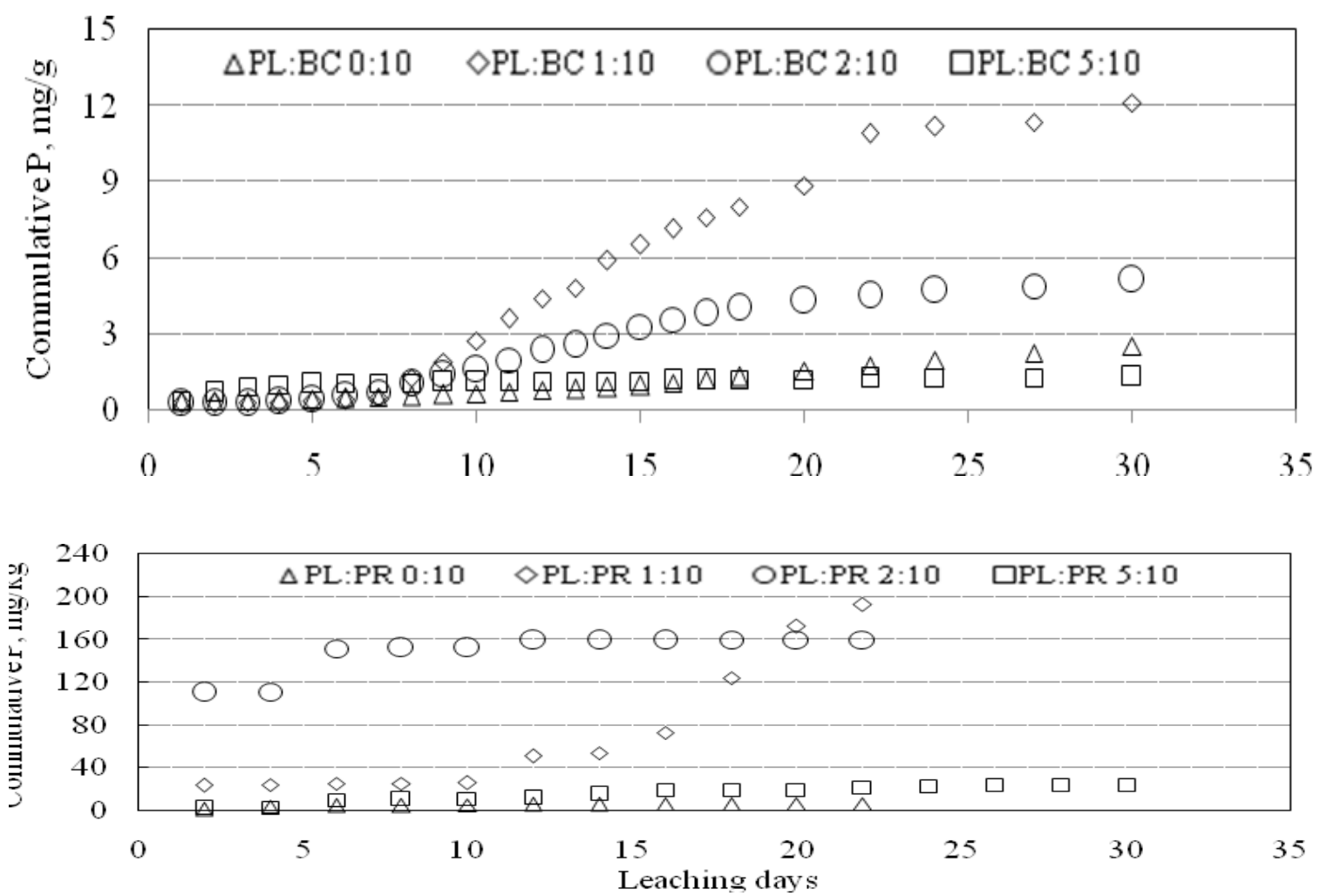

Fig. 1. Cumulative dissolved $P$ by water from $B C$ and $P R$ as a function of the rate of PL addition and leaching time.
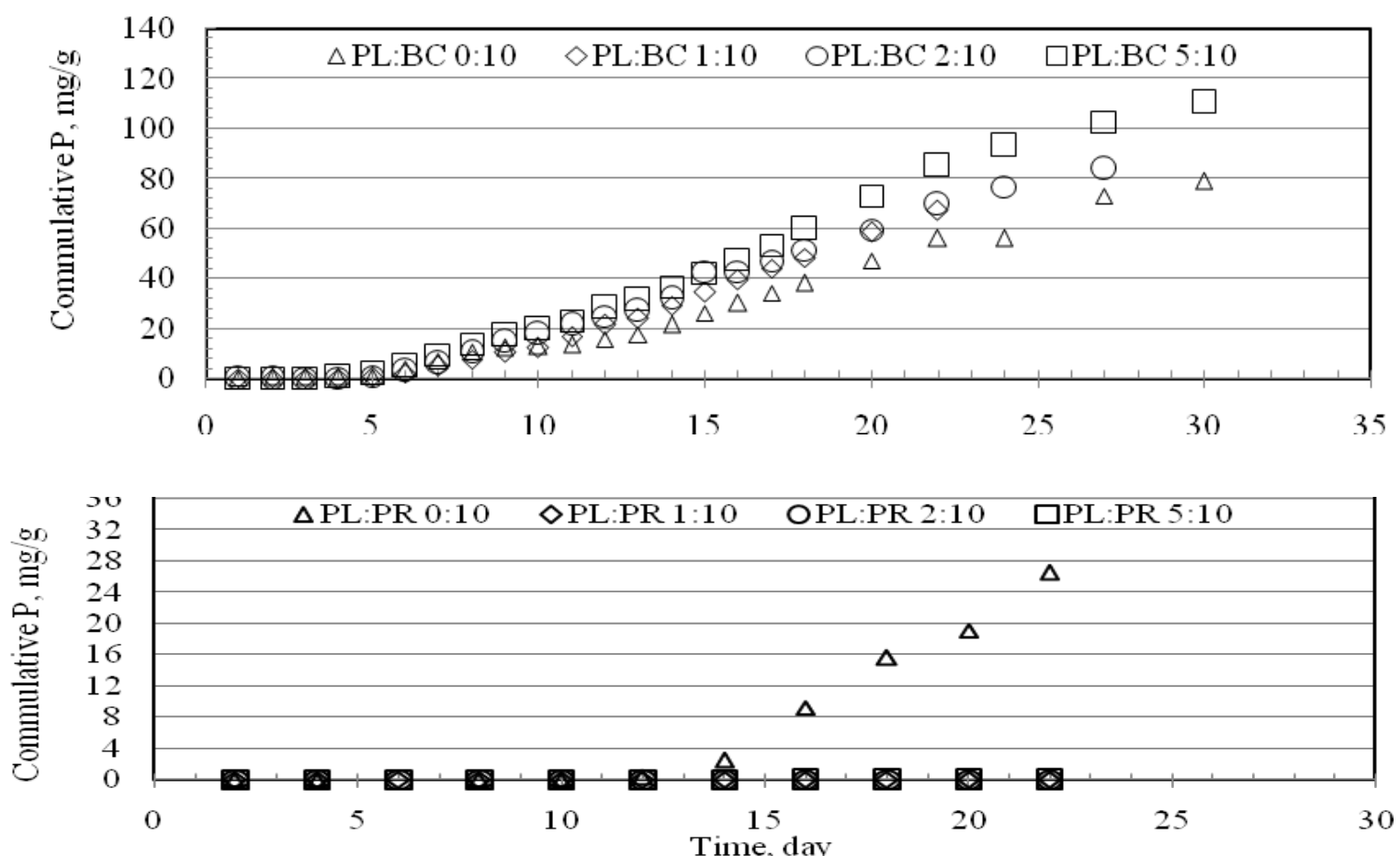

Fig. 2. Cumulative dissolved $P$ by acidified water released from $B C$ and $P R$ as a function of the rate of PL addition and leaching time. 


\section{Conclusion}

The importance of current study concentrates on confirming the feasibility of using bone char as a sustainable resource for $\mathrm{P}$ to satisfy plant requirements. $\mathrm{BC}$ contained higher concentrations of soluble-P than PR. Leaching (e.g., irrigation) with acidified water can play further significant role in increasing P release from $\mathrm{BC}$ than from PR. Mixing poultry manure with studied $\mathrm{BC}$ increased $\mathrm{P}$ solubility and $\mathrm{P}$ uptake by maize plants for all tested ratios whereas mixing PL with PR by $50 \%$ was effective in $\mathrm{P}$ solubilization. Further studies on chemistry of BC-P in calcareous soils and its behavior with soil organic and mineral solids surfaces are needed to set answers on various suspended questions.

\section{References}

Agyin-Birikorang, S., Abekoe, M. K. and Oladeji, O.

O. (2007) Enhancing the agronomic effectiveness of natural phosphate rock with poultry manure: a way forward to sustainable crop production. Nutr. Cycl. Agroecosyst 79,113-123.

Akande, M.O., Adediran, J.A. and Oluwatoyinbo, F.I. (2005) Effects of rock phosphate amended with poultry manure on soil available $\mathrm{p}$ and yield of maize and cowpea. African Journal of Biotechnology. 4, 444-448.

Al-Oud, S.S. (2011) Improving phosphorus availability from phosphate rock in calcareous soils by amending with: organic acid, sulfur, and/or organic manure. Ozean Journal of Applied Sciences 4, 227-235.

Anderson, J.U. (1961) An improved pretreatment for mineralogical analysis of samples containing organic matter. Tenth National Conference on Clays and Clay Minerals Austin, Texas, USA: 380-389

Atienza-Martínez, M., Gea, G., Arauzo J., Kersten, S. R. A., Maarten, A. and Kootstra, J. (2014) Phosphorus recovery from sewage sludge char ash. Biomass and Bioenergy 65, 42 -50.

Bianco C. and Defez, R. (2010) Improvement of Phosphate Solubilization and Medicago Plant Yield by an Indole-3-Acetic Acid-Overproducing Strain of Sinorhizobium meliloti. Applied and Environ. Microbiol., 76, 4626-4632.

Bradley, R. (2014) Bovine Spongiform Encephalopathy (BSE) in: Encyclopedia of the Neurological Sciences (Second Edition), Pp. 452-456. Elsevier.

Brown, B. L., Slaughter, A. D. and Schreiber, M.E. (2005) Controls on roxarsone transport in agricultural watersheds. Applied Geochem., 20, 123-133.

Buss, W., Graham, M.C., Shepherd, J.G. and Mašek, O. (2016) Suitability of marginal biomass-derived biochars for soil amendment. 547, 314-322.

Cascarosa E., Gea, G. and Arauzo, J. (2012) Thermochemical processing of meat and bone meal: A review. Renewable \& Sustainable Energy Reviews 16, 942-957.

Chaala A. and Roy, C. (2003) Recycling of meat and bone meal animal feed by vacuum pyrolysis. Environ. Sci. Technol., 37, 4517-4522.

Chapmann, H.D. and Pratt, P.F. (1961) Methods of Analysis for Soils, Plants and Waters. Div. Agric. Sci., Univ. of California, Berkeley.

Chien, S.H. and Hammond, L. L. (1989) Agronomic effectiveness of partially acidulated phosphate rock as influenced by soil phosphorus-fixing capacity. Plant and Soil. 120, 159-164.

Cordell D., Drangert, J. and White, S. (2009) The Story of Phosphorus: Global food security and food for thought. Global Environmental Change. 19, 292 305 .

Cordell D., Rosemarin, A., Schröder, J. and Smit, A. L. (2011) Towards global phosphorus security: A framework for phosphorus recovery and reuse options. Chemospher.e 84, 747-758.

Costat (1985) User's Manual. Version 3, Cohort. Tucson, Arizona, USA. Development Center, Muscle Shoals, AL 35662, USA.

Crompton, T.R. (2000) Determination of organic compounds in soils, sediments and sludges. Taylor \& Francis Group. London, UK.

Deydier, E., Guilet, R., Sarda, S. and Sharrock, P., (2005) Physical and chemical characterisation of crude meat and bone meal combustion residue: waste or raw material. J. Hazard. Mater. B121, 141- 148.

Duarte, R.F., Santana, C.S., Fernandes, L.A., da Silva, I.C.B., Sampaio, R.A., Frazão ,L.A. (2015) Phosphorus availability from natural and soluble phosphate sources for irrigated corn production. African Journal of Agricultural Research. 10, 3101-3106.

El-Refaey, A. A., Mahmoud, A. H. and Saleh, M. E. (2015) Bone biochar as renewable and efficient $\mathrm{P}$ fertilizer: a comparative Study. Alexandria J. Agric. Res. 60, 127-137. 
European Union (2002)Animal By-Products Regulations (EC) No. 1774/2002. http://eur- lex. europa.eu/LexUriServ/LexUriServ.do?uri=OJ:L:2 002:273:0001:0095:EN:PDF (accessed February, 2016).

Franz, M. (2008) Phosphate fertilizer from sewage sludge ash (SSA). Waste Manag., 28,1809-1818.

Genza ,A., Kornmuller, A. and Jekel, M. (2004) Advanced phosphorus removal from membrane filtrates by adsorption on activated aluminum oxide and granulated ferric hydroxide. Water Res., 38, 3523-3530.

Gilbert, N. (2009) Environment: The disappearing nutrient. Nature. 461,133-143.

Guppy, C.N., Menzies, N.W., Moody, M.W. and Blamey, F.P.C. (2005) Competitive sorption reactions between phosphorus and organic matter in soil. A review. Austr., J. Soil Res., 43, 189-202.

Hinsinger P., Plassard, C., Tang, C. and Jaillard, B. (2003) Origins of root-mediated $\mathrm{pH}$ changes in the rhizosphere and their responses to environmental constraints: A review. Plant Soil. 248, 43- 59.

Hinsinger, P. (2001) Bioavailability of soil inorganic P in the rhizosphere as affected by root-induced chemical changes: a review. Plant Soil 237, 173-195.

Hoffman, E. and Mager, D. (1953) Solubility of phosphoric acid and phosphate rocks. J. Plant Nutr. Soil Sci., 62, 262-264.

Jeng, A. S., Haraldsen, T. K., Grønlund, A. and Pedersen, P.A. (2006) Meat and bone meal as nitrogen and phosphorus fertilizer to cereal and rye grass. Nutr. Cycl. Agroecosyst. 76, 183-191.

Koppelaar, R. H. E. M. and Weikard, H. P. (2013) Assessing phosphate rock depletion and phosphorus recycling options. Global Environmental Change. 23,1454-1466.

Kumar, V., Gilkes, R.J. and Bolland, M.D.A. (1993) The agronomic effectiveness of reactive rock phosphate, partially acidulated rock phosphate and monocalcium phosphate in soils of different $\mathrm{pH}$. Fertilizer Research. 34, 161-171.

LeGeros, R.Z. (1994) Biological and synthetic apatites. In: Brown PW, Brent Constanz (eds) Hydroxyapatite and related materials. CRC Press, Boca Raton, pp. 3-28.

Novotny, E.H., Auccaise, R., Velloso, M.H.R., Corrêa, J.C., Higarashi, M.M., Abreu,V.M.N., Rocha,
J.D. and Kwapinski, W. (2012) Characterization of phosphate structures in biochar from swine bones. Pesq. agropec. bras. 47, 672-676.

Mahimairaja, S., Bolan, N. S. and Hedley, M.J. (1995) Dissolution of phosphate rock during the composting of poultry manure: an incubation experiment. Fertilizer Research. 40,93-104.

Mendes, G.O., Zafra, D.L., Vassilev, N.B., Silva, I.R., Ribeiro, J. J.I. and Costa, M. D. (2014) iochar enhances Aspergillus niger rock phosphate solubilization by increasing organic acid production and alleviating fluoride toxicity. Applied and Environmental Microbiology 80, 3081-3085.

Murphy, J. and Riley, J. P. (1962) A modified single solution method for the determination of phosphate in natural waters. Analytica Chimica Acta. 27, 31-36.

Olsen, S.R. and Sommers, L.E . (1982) Phosphorus. In A.L. Page et al. (ed.) Chemical and microbiological properties. 2nd ed. ASA, Madison, WI. , p. 403-427.

Rittmann B. E., Mayer, B., Westerhoff, P. and Edwards, M. (2011) Capturing the lost phosphorus. Chemosphere. 64, 846-53.

Petzet S., Peplinski, B., Cornel, P. (2012). On wet chemical phosphorus recovery from sewage sludge ash by acidic or alkaline leaching and an optimized combination of both. Water Research. 46,3769- 3780.

Rajan, S.S.S. and Watkinson, J.H. (1992) Unacidulated and Partially acidulated phosphate rock: Agronomic effectiveness and the rates of dissolution of phosphate rock. Fertilizer Research. 33, 267-277.

Rengel,Z. and Marschner, P.(2005) Nutrient availability and management in the rhizosphere: exploiting genotypic differences. New Phytologist.168: 305312.

Saleh M. E., El-Gamal, E.H., Kamh, M.A., Saad, A.F. (2015) Adsorption Characteristics of Phosphorus on Calcite, Mg-calcite and Calcareous Soils: Effect of Dissolved Organic Carbon. Alexandria J. Agric. Res. 60, 269-282.

Sharif M., Burni, T., Wahid, F., Khan, F.,Khan, S., Khan, A. and Shah, A. (2013) Effect of rock phosphate composted with organic materials on yield and phosphorus uptake of wheat and mung bean crops. Pakistan Journal of Botany. 45,1349-1356.

Sharma, S.B., Sayyed, R.Z., Trivedi, M.H. and Gobi, T.A. (2013) Phosphate solubilizing microbes: sustainable approach for managing phosphorus deficiency in agricultural soils. Springer Plus. 2, 587. 
Siebers, N.F. and Leinweber, P. (2013) Bone char: a clean and renewable phosphorus fertilizer with cadmium immobilization capability. Journal of Environmental Quality. 42,405-411.

Smil, V. (2000) Phosphorus in the environment: natural flows and human interferences. Annual Review of Energy and the Environment. 25,53-88.

Stul, M.S. and van Leemput, L, (1982) Particle-size distribution, cation exchange capacity and charge density of deferrated montmorillonites. Clay Miner. 17, 209-215.

Tributh, H. and Lagaly, G. (1986) Aufbereitung und Identifizierung von Boden- und Lagersta"ttentonen. I. Aufbereitung der Proben um Labor. GITFachzeitschrift fur das Laboratorium. 30, 524-529.

Vassilev, N., Martos, E., Mendes, G., Martos, V. and Vassileva, M. ( 2013) Biochar of animal origin: a sustainable solution to the global problem of high grade rock phosphate scarcity? Journal of the Science of Food and Agriculture. 93,1799-1804.

Wang T., Camps-Arbestain M., Hedley M. and Bishop P. (2012) Predicting phosphorus bioavailability from high-ash biochars. Plant Soil, 357, 173-187.

Warren, G. P., Robinson, J. S. and Someus, E. (2009) Dissolution of phosphorus from animal bone char in 12 soils. Nutr.t Cyc. Agroecosyst. 84,167-178.
Weber, B., Stadlbauer, E.A., Schlich, E., Eichenauer, S., Kern, J. and Steffens, D. (2014) Phosphorus bioavailability of biochars produced by thermo-chemical conversion. Journal of Plant Nutrition and Soil Science.177, 84-90.

Wopenka, B. and Pasteris, J.D. (2005) A mineralogical perspective on the apatitein bone. Materials Science and Engineering: C25,131-143.

Xie, H., Han, D., Cheng, J., Zhou, P. and Wang, W. (2015) Fate and Risk Assessment of Arsenic Compounds in Soil Amended with Poultry Litter Under Aerobic and Anaerobic Circumstances. Water, Air, \& Soil Pollution. 226, 390.

Zwetsloot, M. J., Lehmann, J., Bauerle, T., Vanek, S., Hestrin, R. and Nigussie, A. (2016) Phosphorus availability from bone char in a P-fixing soil influenced by root-mycorrhizae-biochar interactions. Plant Soil. 408,95-105.

Zwetsloot, M. J., Lehmann, J. and Solomon, D. (2014) Recycling slaughterhouse waste into fertilizer: how do pyrolysis temperature and biomass additions affect phosphorus availability and chemistry? Journal of the Science of Food and Agriculture. 95, 281-288.

(Received: $14 / 4 / 2017$; accepted:16/7/2017) 